\section{Journal of Computer Networks, Architecture and High Performance Computing}

Volume 3, Number 1, January 2021

https://doi.org/10.47709/cnahpc.v3i1.935
Submitted : 11 February 2021

Accepted : 17 February 2021

Published : 5 March 2021

\title{
A Review of Detection of Pest Problem in Rice Farming by using Blockchain and IoT Technologies
}

\author{
Taufik Hidayat ${ }^{1 *}$, Rahutomo Mahardiko ${ }^{2)}$ \\ 1) Universitas Wiralodra, Indonesia, ${ }^{2}$ Platinumetrix Pte, Ltd, Indonesia \\ ${ }^{1}$ thidayat.ft@unwir.ac.id, ${ }^{2)}$ rahutomo.mahardiko@gmail.com
}

\begin{abstract}
Pest can be a serious topic in agricultural areas especially rice plantations. The pest destroys the plants before harvesting time. Because of the presence of the pest, the yield of agricultural products is decreasing. From a technical point of view, an agricultural professional should identify not only the type of pest that destroys rice plants but also overcome the pest. This research proposes a paper review on pest detection systems by using Blockchain technology and the Internet of Things involving all parties involved. The use of the review is to have a broad overview regarding the functional combination between IoT and Blockchain technologies to reduce the pest problems. Smart contract technology Blockchain may be held to determine automatic alert in the system and know how to resolve the problem accurately and all information is verified by blockchain system without a human interception. IoT devices can be attached to rice plantations to monitor, determine and send the information of the pests. Our paper explains the combination of IoT and Blockchain technologies in order to improve any possibility of success rate by getting the pests. Thus, IoT replaces human manual checking in pest identification to reduce human error. So that, the harvesting time can be increased and the agriculture yields are good. The search comparison results show that ScienceDirect has the highest search value.
\end{abstract}

Keywords: Blockchain, Internet of Things, Agriculture, Pest, Systematic Literature Review

\section{INTRODUCTION}

Recently, IoT has been applied in many sectors. The sectors using IoT are Smart Home, Smart City, Smart Environment and Smart Agriculture (Elijah, Rahman, Orikumhi, Leow, \& Hindia, 2018). As we know about IoT development, IoT can collaborate with Blockchain technology in order to be used in many sectors. An interesting thing about IoT implementation is that IoT can give accurate information through its sensor inside IoT system (Nawandar \& Satpute, 2019). In health care service, Blockchain can be used to record transaction (Wutthikarn \& Hui, 2018). In agriculture, especially in food supply chain management, the implementation of Blockchain-based IoT makes delivery order, transaction and shipments more reliable (Caro, Ali, Vecchio, \& Giaffreda, 2018).

Smart Agriculture is not only used for agricultural food but also pest detection. By using IoT implementation based Blockchain, a farmer can be helped in tackling pest problems. It is because pest problems can be found in every rice fields (Özyllmaz \& Yurdakul, 2017). Various kind of pest that are attacking rice fields are rat, slug, plant hopper, stink bugs, and birds. With the presence of Blockchain-based IoT technology, most of problem in agriculture, specifically in rice plants could be solved. The implementation of Blockchain-based IoT for pest detection system in rice plants can give a symptom alert. Besides that, combination of these technologies can reach out more broadly in warning data processing and give better information about pest alert.

State-of-the-art in this research is efficiency in crop and livestock operational/production through IoT development (Elijah et al., 2018). IoT-based irrigation control system for decision making on irrigation system is the research target (Nawandar \& Satpute, 2019). Blockchain-based development to record transaction of health care service was researched for better health-care (Wutthikarn \& Hui, 2018). The result of the study is Blockchain-based IoT technology integration (Agri Food system) to detect transparent transaction, less error, and unchangeable transaction for audit purpose (Caro et al., 2018).

The main target of the study is to configure IoT as Blockchain node and event-based messaging mechanism for low-power IoT (Özyılmaz \& Yurdakul, 2017). Blockchain-based food tracking application to improve trackable, efficient, and safe delivery is the state-of-the-art of the research (Kim, Hilton, Burks, \& Reyes, 2018). Intersection problem between IoT operation and Blockchain is the result of the research (Karlsson et al., 2018). Main problem that

* Corresponding author

This is an Creative Commons License This work is licensed under a Creative

Commons Attribution-NoDerivatives 4.0 International License. 
should be overcome is data validation on IoT device by Blockchain (Asare, Quist-Aphetsi, \& Nana, 2019). Tamperproof copy by Blockchain for product history is overcome by the study (Arena, Bianchini, Perazzo, Vallati, \& Dini, 2019).

Every aspect improvement on IoT device by blockchain application is the state-of-the-art of the study (Reyna, Martín, Chen, Soler, \& Díaz, 2018). The state-of-the-art is security enhancement of IoT platform by using Blockchain (Urien, 2018). Blockchain-based authentication for securing IoT is overcome for the study (Yetis \& Sahingoz, 2019). From the study of literature, we do not find the research for detection of pest problem especially in rice farming. Therefore, we will review and explain what should be done for pest detection by using Blockchain and IoT technologies in table 1 . The rest of the paper is research method, result and discussion, and conclusion.

\section{Internet of Things based Blockchain}

\section{LITERATURE REVIEW}

It is a component of a system that contains logics and also implemented in a smart contract of blockchain as a gateway to the blockchain itself. Based on blockchain chosen, a module can have many varieties and complexities in accordance with the capabilities of the blockchain program and client interface (Dittmann \& Jelitto, 2019). Blockchain can be said as a decentralized database and the data is stored in a network. Blockchain technology may a user do peer to peer transaction (Singh, Singh, \& Kim, 2018). Figure 1 describes IoT technology based blockchain structure:



Fig. 1 Blockchain Network for IoT (Singh et al., 2018)

Blockchain are blocks that are cryptographically connected and a collection of time originating from transactions. Each block is identified by a node in a system to prevent malicious attacks (Özyılmaz \& Yurdakul, 2017). The blockchain technology used is useful for IoT by providing service sharing, where information is reliable and can be tracked. Data sources can also be identified at any time and do not change over time for improving security (Reyna et al., 2018). IoT security is increasing with this blockchain technology. Key characteristics of the blockchain include (Khanna \& Kaur, 2019), (Puranik, Sharmila, Ranjan, \& Kumari, 2019).

\section{Internet of Things of Agriculture}

IoT technology plays a very important role in agriculture. This can happen because several device automations with IoT can be well established as well as several other advantages (Puranik et al., 2019):

1. Have connectivity from various devices

2. Minimize human labor or farmers

3. Have rapid capability and access to soil fertility that can be monitored remotely

4. Save time for farmers to monitor during the agricultural process

5. Able to analyze rainfall, soil moisture, texture and well development for pest detection

Because of high quality and quantity increment in food sector, there is a need of technology investment that can improve the quality with smart agriculture of IoT (Suciu, Istrate, \& Ditu, 2019). In addition, smart agriculture of IoT can be integrated by other technology for increasing agricultural productivity and efficiency. IoT technology can be classified into 3 functionalities: (1) IoT for data collection, (2) IoT for data analysis and (3) IoT for decision making 
(Kour, Kour, \& Singh, 2019). Another IoT functionalities are to monitor irrigation water, plants and livestock and pest control (Srinivasulu, Babu, Venkat, \& Rajesh, 2017).

Development of intelligent farming systems uses sensors and microcontrollers in IoT system. The intelligent ability of the microcontroller is to make the decision that must be taken to watering the plants based on continuous monitoring of environmental conditions. It also aims to have a predetermined irrigation schedule at the farmer's convenience and uploads it into an application developed for the same things (Sushanth \& Sujatha, 2018).

\section{METHOD}

Systematic Literature Review (SLR) is a formal method to answer research question (Hidayat, Azzery, \& Mahardiko, 2019), (Hidayat, 2017). The used method is for studying past research in IoT with Blockchain for pest detection (Ferrag, Shu, Yang, Derhab, \& Maglaras, 2020). 5 steps for SLR are (1) declaration of study question, (2) digital library selection, (3) extraction of the paper, (4) synthesis, and (5) result and discussion (Aly, Khomh, Haoues, Quintero, \& Yacout, 2019), (Hidayat \& Mahardiko, 2020). Table 1 is research question based on gap analysis.

Table 1

Research Question of the Paper

\begin{tabular}{ll}
\hline \hline Question & \multicolumn{1}{c}{ Achievement / Purpose } \\
\hline What is Blockchain-based IoT? & Define the combination of smart technology system \\
What is pest detection system for rice farming? & Identify blockchain-based IoT for pest detection in rice farming \\
What is the contribution of the research? & $\begin{array}{l}\text { The contribution is blockchain-based IoT is able to detect pest } \\
\text { in rice farming. It also can enhance agriculture yield }\end{array}$ \\
\hline
\end{tabular}

To answer the defined question in table 1, 4 trusted libraries will support the research (Hidayat \& Mahardiko, 2020). Table 2 is link of digital library for the study.

Table 2

Trusted Digital Library

\begin{tabular}{ll}
\hline \multicolumn{1}{c}{ Digital Library } & \multicolumn{1}{c}{ URL Link } \\
\hline Wiley & onlinelibrary.wiley.com \\
IEEE & ieexplore.iee.org \\
ScienceDirect & www.sciencedirect.com \\
Tandfonline & www.tandfonline.com \\
\hline
\end{tabular}

Table 2 explains some trusted digital libraries for the research (Hidayat, Mahardiko, and Franky, D, Sianturi 2020). We search related paper from 2015 to 2019. As per the reason, the libraries produce high quality paper (Lakhiar et al., 2018). Figure 1 is SLR step for the research.

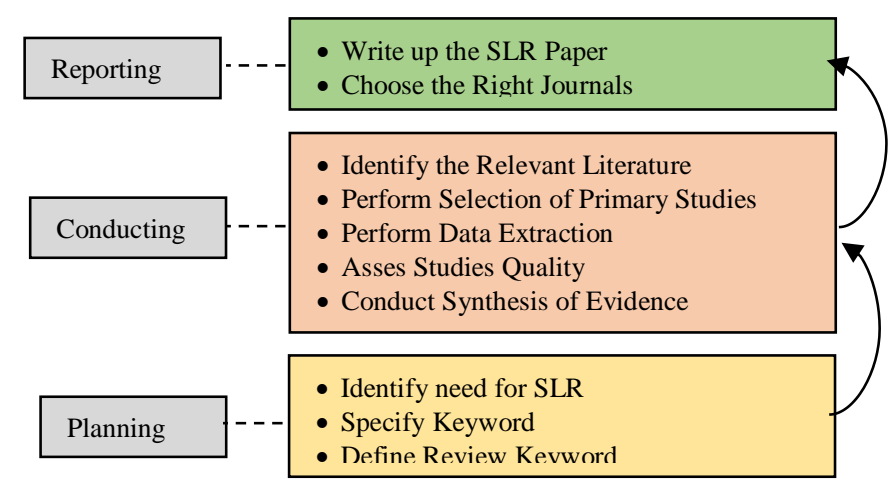

Fig. 2 SLR Processing Method (Hidayat et al., 2020) 
Figure 2 explains our step for working on SLR method. Planning step describes identification of SLR needs, library determination and keyword specification. Conducting step tells relevant literature determination, extraction and synthesis. Reporting step writes the paper of the report study.

First step is planning. Table 1 and 2 are also our planning of SLR that must be overcome. Then, we have to define some criteria to divide (Hidayat et al. 2020) unrelated and related papers (Mahmoud Abbasi, Mohammad Hossein Yaghmaee, 2018). To improve of success rate during paper identification, quantity and quality assessment must be defined (Khanna \& Kaur, 2019). Table 3 describes the criteria.

Table 3

Defined Criteria Research

\begin{tabular}{ll}
\hline Code & Defined Criteria Research \\
\hline RE1 & Up to date content \\
RE2 & Published paper between 2015 to 2019 \\
RE3 & Paper discussion on Agriculture \\
RE4 & Paper discussion on IoT \\
RE5 & Paper discussion on Blockchain \\
Code & $\quad$ Unreliable \\
UR1 & Out of date paper \\
UR2 & Not related discussion in paper \\
UR3 & Not English paper \\
UR4 & Poor quality of paper \\
Code & $\quad$ Quantity Description \\
QND1 & Number as measurement? \\
QND2 & Measurement process definition? \\
QND3 & Measurement standards? \\
Code & \\
QLD1 & Enough description in context? \\
QLD2 & Reviewed paper from last research? \\
QLD3 & Strength and weakness of objectives? \\
QLD4 & Result research? \\
\hline &
\end{tabular}

Based on research criteria in table 3, it amplifies the answer in table 1. In addition, table 1 also can be summarized as "Rice Farming by using Blockchain and IoT technologies". The conducting activity must be followed for having relevant paper. We did the research in $11^{\text {th }}$ December 2020. From the activity, we conclude some results of 4 trusted digital libraries.

Table 4

The Paper Search Results

\begin{tabular}{lc}
\hline Database & The Number of Paper \\
& \\
\hline Wiley & 68 \\
IEEE & 3 \\
ScienceDirect & 53 \\
Tandfonline & 13 \\
Total & 137 \\
\hline
\end{tabular}

Table 4 explains research result for "Farming by using Blockchain and IoT technologies". We have journals for the analysis. 


\section{RESULT}

We do step by step in figure 2 by defining blockchain and IoT as the main keyword.

\section{Data Source for Paper Selection}

4 trusted libraries named "Wiley", "IEEE", "ScienceDirect", and "Tandfonline is our library databases for the research. The link can be seen in table 2. The search process is done in $11^{\text {th }}$ December 2020 ranging 2015 to 2019. The keywords are "Blockchain Internet of Things", "Blockchain and Internet of Things agriculture", and "Blockchain and Internet of Things Agriculture Farming". All keywords are lowercase with space and without quotation mark.

We classify the keywords into 3 classifications. First is Q1 (Blockchain Internet of Things). Second part is Q2 (Blockchain and Internet of Things agriculture). Third area is Q3 (Blockchain and Internet of Things agriculture detection pest problem). Besides that, we classify the keywords, we also classify the libraries. DL1 (Wiley), DL2 (IEEE), DL3 (ScienceDirect) and DL4 (Tandfonline) are our classifications. The keywords are being used to search relevant paper to support this paper and we only define journal article and paper conference.

Table 5

Search Results on Digital Library

\begin{tabular}{ccccc}
\hline \multirow{2}{*}{ Keyword } & \multicolumn{4}{c}{ Digital Library } \\
& DL1 & DL2 & DL3 & DL4 \\
\hline Q1 & 210 & 1017 & 617 & 220 \\
Q2 & 50 & 15 & 119 & 25 \\
Q3 & 7 & 5 & 34 & 11 \\
\hline
\end{tabular}

Table 5 answers the research's questions that shows whether there is chance in this research to detect the pest problem using Blockchain and IoT devices in rice farming. Figure 2 gives holistic view of Blockchain and IoT based on table 5.

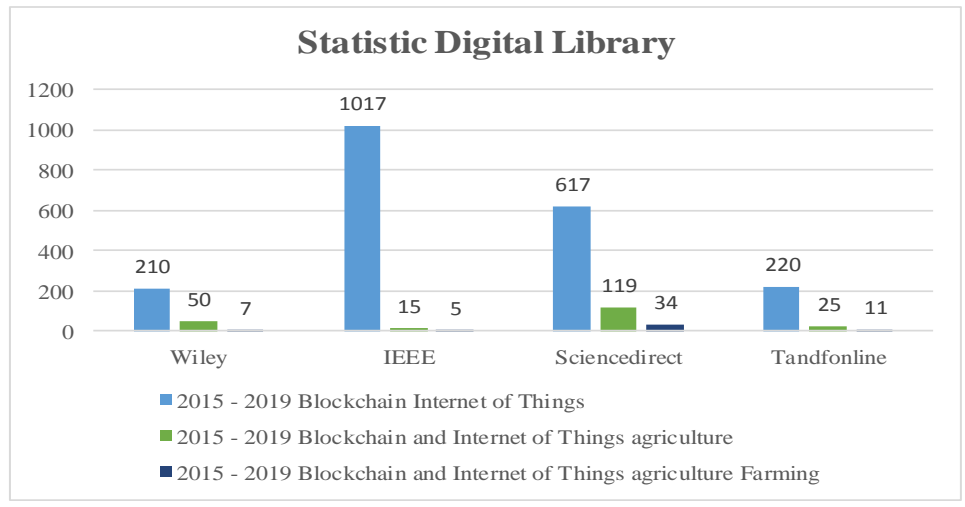

Fig. 3 SLR Statistic Digital Library

Both, Table 5 and Fig. 3, show that only 57 papers are detected on very deep analysis. The use Blockchain and IoT can be enhanced for better agriculture especially pest detection. Rat and mouse movement detection system using blockchain and IoT system in rice field plantation can be the example. Other example is the use drone to detect pest using Blockchain and IoT. This research result may also be used for better other topic.

\section{Blockchain and Internet of Things Comparison in Agriculture}

We intend to use SLR because of the need of transaction transparency on Internet of Things Agriculture. So, the paper will resolve agriculture problem by using IoT and Blockchain. To resolve the problem, we have an approach to determine relevant problem and find related paper. All collected papers are coming from 4 digital libraries during 2015 to 2019. Related journals for IoT are $20 \%$ and Blockchain are 5\%. SLR comparison can be seen in table 6 . 
Table 6

Comparison SLR Internet of Things on Blockchain

\begin{tabular}{lcc}
\hline \hline \multicolumn{1}{c}{ Description } & Internet of Things on Blockchain & Internet of Things on Blockchain Agriculture \\
\hline $\begin{array}{l}\text { Research Question } \\
\text { Search Strategy Paper }\end{array}$ & $\begin{array}{c}\text { Up to } 9 \\
\text { Keyword based on authors and } \\
\text { keyword theme scope } \\
\text { Model of String Keyword }\end{array}$ & $\begin{array}{c}\text { Only 2 } \\
\text { specific subject scope }\end{array}$ \\
Resource to be used for Search Paper & 4 Libraries of Digital online & 1 Model of string \\
& 5 in unreliable criteria & 2 Libraries of Digital online \\
Paper Selection Criteria & 4 in reliable criteria & 2 in unreliable criteria \\
& 4 in quality description & 2 in reliable criteria \\
& 3 in quantity description & 1 in quality description \\
\end{tabular}

Table 6 explains relevant papers with several defined criteria. Q3 in table 5 has 57 papers, we then extracted some papers. Table 7 explains each definition, such as: Blockchain and Internet of Things agriculture detection pest problem and quantity measurement.

Table 7

Result of Journal Review

\begin{tabular}{|c|c|c|c|}
\hline \multirow[b]{2}{*}{ Paper } & \multicolumn{3}{|c|}{ Scope of Paper } \\
\hline & IoT Blockchain & Smart Agriculture & Quantity Measurement \\
\hline (Caro et al., 2018) & $\mathrm{V}$ & $\mathrm{v}$ & $\mathrm{x}$ \\
\hline (Kim et al., 2018) & $\mathrm{V}$ & $\mathrm{x}$ & $\mathrm{v}$ \\
\hline (Karlsson et al., 2018) & $\mathrm{V}$ & $\mathrm{x}$ & $\mathrm{x}$ \\
\hline (Asare et al., 2019) & $\mathrm{V}$ & $\mathrm{x}$ & $\mathrm{v}$ \\
\hline (Arena et al., 2019) & $\mathrm{V}$ & $\mathrm{x}$ & $\mathrm{v}$ \\
\hline (Yetis \& Sahingoz, 2019) & $\mathrm{V}$ & $\mathrm{x}$ & $\mathrm{v}$ \\
\hline (Sinha, Shrivastava, \& Kumar, 2019) & $\mathrm{X}$ & $\mathrm{v}$ & $\mathrm{v}$ \\
\hline $\begin{array}{l}\text { (Tzounis, Katsoulas, Bartzanas, \& } \\
\text { Kittas, 2017) }\end{array}$ & $\mathrm{X}$ & $\mathrm{v}$ & $\mathrm{v}$ \\
\hline $\begin{array}{c}\text { (Codeluppi, Cilfone, Davoli, \& } \\
\text { Ferrari, 2019) }\end{array}$ & $\mathrm{V}$ & $\mathrm{v}$ & $\mathrm{x}$ \\
\hline $\begin{array}{l}\text { (Satapathy, Mohanta, Panda, } \\
\text { Sobhanayak, \& Jena, 2019) }\end{array}$ & V & $\mathrm{x}$ & $\mathrm{x}$ \\
\hline (Khanna \& Kaur, 2019) & $\mathrm{X}$ & $\mathrm{v}$ & $\mathrm{v}$ \\
\hline (Gill et al., 2019) & $\mathrm{V}$ & $\mathrm{x}$ & $\mathrm{v}$ \\
\hline $\begin{array}{l}\text { (Verdouw, Sundmaeker, } \\
\text { Tekinerdogan, Conzon, \& } \\
\text { Montanaro, 2019) }\end{array}$ & $\mathrm{V}$ & $\mathrm{v}$ & $\mathrm{x}$ \\
\hline Paper & $\mathrm{V}$ & $\mathrm{v}$ & $\mathrm{v}$ \\
\hline
\end{tabular}

Based on table 7, we propose all categories that should be done for pest detection system. Thus, the production of agriculture can increase well.

\section{CONCLUSION}

Blockchain technology and IoT may build pest detection system for rice plants in non-trusted ecosystem. We use IoT in order to record and verify pest problem with minimal human efforts. In future, smart contract technology may be held to determine automatic alert in system and know how to resolve the problem accurately. Research with the 


\section{Journal of Computer Networks, Architecture and High Performance Computing}

Volume 3, Number 1, January 2021

https://doi.org/10.47709/cnahpc.v3i1.935
Submitted : 11 February 2021

Accepted : 17 February 2021

Published : 5 March 2021

SLR method from 2015 to 2019 which consists of 4 digital libraries shows that research related to Blockchain in agriculture is still interesting for further study.

\section{ACKNOWLEDGMENT}

The authors would like to thank civitas Department of Computer Engineering, Universitas Wiralodra for the support of this research.

\section{REFERENCES}

Aly, M., Khomh, F., Haoues, M., Quintero, A., \& Yacout, S. (2019). Enforcing security in Internet of Things frameworks: A Systematic Literature Review. Internet of Things, 6, 100050. doi: 10.1016/j.iot.2019.100050

Arena, A., Bianchini, A., Perazzo, P., Vallati, C., \& Dini, G. (2019). BRUSCHETTA: An IoT Blockchain-Based Framework for Certifying Extra Virgin Olive Oil Supply Chain. 2019 IEEE International Conference on Smart Computing (SMARTCOMP), 173-179. IEEE. doi: 10.1109/SMARTCOMP.2019.00049

Asare, B. T., Quist-Aphetsi, K., \& Nana, L. (2019). Nodal Authentication of IoT Data Using Blockchain. 2019 International Conference on Computing, Computational Modelling and Applications (ICCMA), 125-1254. IEEE. doi: 10.1109/ICCMA.2019.00028

Caro, M. P., Ali, M. S., Vecchio, M., \& Giaffreda, R. (2018). Blockchain-based traceability in Agri-Food supply chain management: A practical implementation. 2018 IoT Vertical and Topical Summit on Agriculture - Tuscany (IOT Tuscany), 1-4. IEEE. doi: 10.1109/IOT-TUSCANY.2018.8373021

Codeluppi, G., Cilfone, A., Davoli, L., \& Ferrari, G. (2019). VegIoT Garden: a modular IoT Management Platform for Urban Vegetable Gardens. 2019 IEEE International Workshop on Metrology for Agriculture and Forestry (MetroAgriFor), 121-126. IEEE. doi: 10.1109/MetroAgriFor.2019.8909228

Dittmann, G., \& Jelitto, J. (2019). A Blockchain Proxy for Lightweight IoT Devices. 2019 Crypto Valley Conference on Blockchain Technology (CVCBT), 1-4. doi: 10.1109/CVCBT.2019.00010

Elijah, O., Rahman, T. A., Orikumhi, I., Leow, C. Y., \& Hindia, M. N. (2018). An Overview of Internet of Things (IoT) and Data Analytics in Agriculture: Benefits and Challenges. IEEE Internet of Things Journal, 5(5), 37583773. doi: 10.1109/JIOT.2018.2844296

Ferrag, M. A., Shu, L., Yang, X., Derhab, A., \& Maglaras, L. (2020). Security and Privacy for Green IoT-Based Agriculture: Review, Blockchain Solutions, and Challenges. IEEE Access, 8, 32031-32053. doi: 10.1109/ACCESS.2020.2973178

Gill, S. S., Tuli, S., Xu, M., Singh, I., Singh, K. V., Lindsay, D., ... Garraghan, P. (2019). Transformative effects of IoT, Blockchain and Artificial Intelligence on cloud computing: Evolution, vision, trends and open challenges. Internet of Things, 8,100118 . doi: 10.1016/j.iot.2019.100118

Hidayat, T. (2017). Internet of Things Smart Agriculture on ZigBee: A Systematic Review. Jurnal Telekomunikasi Dan Komputer, 8(1), 75. doi: 10.22441/incomtech.v8i1.2146

Hidayat, T., Azzery, Y., \& Mahardiko, R. (2019). Load Balancing Network by using Round Robin Algorithm: A Systematic Literature Review. Jurnal Online Informatika, 4(2), 85-89. doi: 10.15575/join.v4i2.446

Hidayat, T., \& Mahardiko, R. (2020). A Systematic Literature Review Method On AES Algorithm for Data Sharing Encryption On Cloud Computing. International Journal of Artificial Intelligence Research, 4(1), 49-57. doi: 10.29099/ijair.v4i1.154

Hidayat, T., Mahardiko, R., \& D, S. T. F. (2020). Method of Systematic Literature Review for Internet of Things in ZigBee Smart Agriculture. 2020 8th International Conference on Information and Communication Technology (ICoICT), 1-4. IEEE. doi: 10.1109/ICoICT49345.2020.9166195

Karlsson, K., Jiang, W., Wicker, S., Adams, D., Ma, E., van Renesse, R., \& Weatherspoon, H. (2018). Vegvisir: A Partition-Tolerant Blockchain for the Internet-of-Things. 2018 IEEE 38th International Conference on Distributed Computing Systems (ICDCS), 2018-July, 1150-1158. IEEE. doi: 10.1109/ICDCS.2018.00114

Khanna, A., \& Kaur, S. (2019). Evolution of Internet of Things (IoT) and its significant impact in the field of Precision Agriculture. Computers and Electronics in Agriculture, 157(December 2018), 218-231. doi: 10.1016/j.compag.2018.12.039

Kim, M., Hilton, B., Burks, Z., \& Reyes, J. (2018). Integrating Blockchain, Smart Contract-Tokens, and IoT to Design a Food Traceability Solution. 2018 IEEE 9th Annual Information Technology, Electronics and Mobile Communication Conference (IEMCON), 335-340. IEEE. doi: 10.1109/IEMCON.2018.8615007 
Lakhiar, I. A., Jianmin, G., Syed, T. N., Chandio, F. A., Buttar, N. A., \& Qureshi, W. A. (2018). Monitoring and Control Systems in Agriculture Using Intelligent Sensor Techniques: A Review of the Aeroponic System. Journal of Sensors, 2018, 1-18. doi: 10.1155/2018/8672769

Mahmoud Abbasi, Mohammad Hossein Yaghmaee, F. R. (2018). Internet of things in agriculture: A review. Third International Conference on Internet of Things and Applications, (of), 1-12. doi: 10.18805/ag.R-1836

Nawandar, N. K., \& Satpute, V. R. (2019). IoT based low cost and intelligent module for smart irrigation system. Computers and Electronics in Agriculture, 162(December 2018), 979-990. doi: 10.1016/j.compag.2019.05.027

Özyılmaz, K. R., \& Yurdakul, A. (2017). Integrating low-power IoT devices to a blockchain-based infrastructure. Proceedings of the Thirteenth ACM International Conference on Embedded Software 2017 Companion EMSOFT '17, 1-2. New York, New York, USA: ACM Press. doi: 10.1145/3125503.3125628

Puranik, V., Sharmila, Ranjan, A., \& Kumari, A. (2019). Automation in Agriculture and IoT. 2019 4th International Conference on Internet of Things: Smart Innovation and Usages (IoT-SIU), 1-6. IEEE. doi: 10.1109/IoTSIU.2019.8777619

Reyna, A., Martín, C., Chen, J., Soler, E., \& Díaz, M. (2018). On blockchain and its integration with IoT. Challenges and opportunities. Future Generation Computer Systems, 88(2018), 173-190. doi: 10.1016/j.future.2018.05.046

Satapathy, U., Mohanta, B. K., Panda, S. S., Sobhanayak, S., \& Jena, D. (2019). A Secure Framework for Communication in Internet of Things Application using Hyperledger based Blockchain. 2019 10th International Conference on Computing, Communication and Networking Technologies (ICCCNT), 1-7. IEEE. doi: 10.1109/ICCCNT45670.2019.8944811

Singh, M., Singh, A., \& Kim, S. (2018). Blockchain: A game changer for securing IoT data. IEEE World Forum on Internet of Things, WF-IoT 2018 - Proceedings, 2018-Janua, 51-55. doi: 10.1109/WF-IoT.2018.8355182

Sinha, A., Shrivastava, G., \& Kumar, P. (2019). Architecting user-centric internet of things for smart agriculture. Sustainable Computing: Informatics and Systems, 23, 88-102. doi: 10.1016/j.suscom.2019.07.001

Sushanth, G., \& Sujatha, S. (2018). IOT Based Smart Agriculture System. 2018 International Conference on Wireless Communications, Signal Processing and Networking (WiSPNET), 1-4. IEEE. doi: 10.1109/WiSPNET.2018.8538702

Tzounis, A., Katsoulas, N., Bartzanas, T., \& Kittas, C. (2017). Internet of Things in agriculture, recent advances and future challenges. Biosystems Engineering, 164, 31-48. doi: 10.1016/j.biosystemseng.2017.09.007

Urien, P. (2018). Blockchain IoT (BIoT): A New Direction for Solving Internet of Things Security and Trust Issues. 2018 3rd Cloudification of the Internet of Things (CIoT), 1-4. IEEE. doi: 10.1109/CIOT.2018.8627112

Verdouw, C., Sundmaeker, H., Tekinerdogan, B., Conzon, D., \& Montanaro, T. (2019). Architecture framework of IoT-based food and farm systems: A multiple case study. Computers and Electronics in Agriculture, 165(July), 104939. doi: 10.1016/j.compag.2019.104939

Wutthikarn, R., \& Hui, Y. G. (2018). Prototype of Blockchain in Dental care service application based on Hyperledger Composer in Hyperledger Fabric framework. 2018 22nd International Computer Science and Engineering Conference (ICSEC), 1-4. IEEE. doi: 10.1109/ICSEC.2018.8712639

Yetis, R., \& Sahingoz, O. K. (2019). Blockchain Based Secure Communication for IoT Devices in Smart Cities. 2019 7th International Istanbul Smart Grids and Cities Congress and Fair (ICSG), 134-138. IEEE. doi: 10.1109/SGCF.2019.8782285 